\title{
The impact of supply chain financing on SMEs performance in Global supply chain
}

\author{
Trong Lam Vu ${ }^{a}$, Duy Nhien Nguyen ${ }^{b}$, Tuan Anh Luongc, Thi Thanh Xuan Nguyen ${ }^{d}$, Thi Thai Thuy \\ Nguyen $^{\mathrm{e}}$ and Thi Diep Uyen Doan ${ }^{\mathrm{e}}$
}

\author{
${ }^{a}$ Communist Review, Vietnam \\ ${ }^{b}$ Hanoi National University of Education, Vietnam \\ ${ }^{c}$ University Of Kinh Bac, Vietnam \\ ${ }^{d}$ Dai Nam University, Vietnam \\ CH R O N I C L E

\begin{tabular}{l} 
Article history: \\
Received September 18, 2020 \\
Received in revised format May 8, \\
2021 \\
Accepted September 32021 \\
Available online \\
September 32021 \\
\hline Keywords: \\
Supply chain finance \\
Supply chain management \\
SMES \\
Vietnam
\end{tabular}

eUniversity of Economics - Technology for Industries

\section{A B S T R A C T}

The purpose of the article is to evaluate the factors affecting supply chain finance and the influence of supply chain finance on supply chain financing performance and SMEs performance in Vietnam. The study was conducted on 856 small and medium enterprises in Vietnam for 3 consecutive months. The data is processed by Smart PLS 3.3.6 software, the results show that credit quality, supply chain integration, information sharing, and information technology all have a statistically significant impact on supply chain finance. Besides, supply chain finance has a statistically significant impact on supply chain financing performance and SMEs performance. Finally, the innovation capability and the market response capability act as full mediators in the relationship between supply chain finance and supply chain financing performance. Based on the research results, we propose solutions and recommendations to help small and medium enterprises better access capital and improve business performance.

\section{Introduction}

In an export-oriented economy like Vietnam, if supply chain financing products are available, it will help domestic businesses strengthen their links with global supply chains. However, at present, very few financial institutions in Vietnam provide modern supply chain financing services on a large scale due to difficulties in scale and capacity. Facing the trend of globalization and expanding international trade, banks have stepped up the supply of seller factoring products in supply chain financing to support businesses. Over the past few years, supply chain financing has become increasingly popular, in part due to increasing globalization and the greater complexity of supply chains, especially in industries. industries such as the automotive, manufacturing and retail sectors. Supply chain financing is a new approach of the bank in providing financial support to businesses with a win-win perspective. Specifically, businesses will be selected by banks, and support working loans to sell and purchase goods for their suppliers or distributors. The appearance of large investment projects from multinational corporations such as Samsung, LG, Microsoft, Intel or Mitsubishi Heavy Industries in Vietnam is being considered as a golden opportunity for domestic enterprises to participate in global supply chain. In the current trend of globalization, competition between domestic and foreign enterprises is inevitable and a fundamental factor for successful competitive manufacturing enterprises today is to have an efficient supply chain. Indeed, in the process of operating a business, when optimizing the supply chain, it will help businesses reduce significantly in terms of financial costs in business; while helping to improve flexibility, time efficiency and service quality. Supply chain management is associated with almost all activities of manufacturing enterprises, from planning and managing the process of sourcing goods, purchasing, producing finished products for each material, logistics management, coordination with partners, suppliers, intermediaries, service providers and customers. The fact has shown that successful and famous global brands such as Apple, Amazon, Unilever,

* Corresponding author Tel.: +84-932 232356

E-mail address: dtduyen@uneti.edu.vn (T. D. U. Doan)

(c) 2022 Growing Science Ltd. All rights reserved.

doi: $10.5267 /$ j.uscm.2021.9.003 
Intel, Nike, Walmart, Samsung are also the best supply chains in the world. In Vietnam, this closed chain model is being applied in production and business enterprises in the fields of animal husbandry, apparel, nutritional food processing, real estate, etc. by the requirement to control the source of raw materials and finished products with competitive prices, especially to ensure the quality of clean and good products to consumers. Therefore, many businesses are actively investing in the supply chain to find business advantages in the Vietnamese market as well as for export.

Supply Chain Financing is an important part of Supply Chain Management that helps connect buyers, sellers and financial sponsors. Supply chain financing helps businesses reduce financial costs and improve business performance. It also helps to release working capital that is "stuck" in the supply chain. Supply chain financing is a service that can be applied to both small and medium enterprises and large enterprises. Supply chain financing has become extremely popular thanks to the level of security and convenience they bring to business transactions and import and export transactions on a global scale. At the same time, this service is also quite safe for business transactions. In other words, supply chain financing benefits all parties. Supply chain financing products not only help domestic manufacturers and exporters strengthen their links with global supply chains, but also help credit institutions extend credit to participating customers' supply chains. However, there are very few financial institutions in Vietnam that provide modern supply chain financing on a large scale. Over a long history of development, small and medium enterprises (SMEs) in developed and developing countries are considered as an important force in terms of economic and social problems. SMEs operating in all areas of the national economy from industrial production, construction, trade, and services not only play a big role in economic development but also contribute to solving many social problems. In the current trend of integration and globalization, countries in general and developing countries in particular pay attention to supporting SMEs, in order to maximize resources to participate in the development of the country. The objective of the article is to evaluate the positive effects of supply chain financing on Vietnamese small and medium enterprises when participating in the domestic supply chain towards the global supply chain.

\section{Literature review}

\subsection{Supply chain management}

Supply chain is a term associated with the import and export industry, also known internationally as Logistics. In simple terms, a supply chain is a network that connects goods suppliers or manufacturers with companies and businesses (Phan et al., 2019). The supply chain occupies an irreplaceable position for business enterprises, especially manufacturing enterprises. In addition, units in the forwarding, freight forwarding, and supply chain operations help deliver goods to target customers and consumers quickly and in a timely manner (Le et al., 2019). Supply chain management includes all logistics management activities including planning and managing all activities related to sourcing and purchasing, including all Logistics activities. More importantly, it also includes coordination and cooperation with partners in a comprehensive supply chain, which can be suppliers, third-party service providers, and customers (Tran et al., 2020). In essence, supply chain management integrates supply and demand management within and between different companies. Thus, supply chain management is the management of all activities related to the supply chain such as planning, developing supply chain implementation strategies, monitoring and measuring performance, and conducting adjustments when something goes wrong. The timely, accurate and timely supply and distribution of products is greatly determined by the effectiveness of supply chain management activities. We have somewhat understood the role and meaning of the supply chain in the operation of goods. A professionally operated supply chain makes deliveries quick and timely. Then customers will feel satisfied and love your business. Supply chain management is said to be an indirect solution to build a business brand without having to invest in marketing activities. Besides, after-sale customer care services will be easier to perform with the help of a professional supply chain. Supply chain management can reduce purchasing costs based on the principle of reducing time and personnel for inventory activities and the cost of renting locations and warehouses. When your business has a professional and reliable supply chain supplier, you will not need to worry about storing goods and production materials. As a result, other related costs will be minimized. Supply chain management is an integrated function with the responsibility of connecting key business functions and business processes within companies into a cohesive and high-performance business model. It includes all the logistics management activities noted above, as well as the manufacturing operations, and promotes the coordination of the processes and activities of the marketing, sales, and design departments. products, finance, information technology. Whether the supply chain is good or not directly affects the production and business activities of enterprises. Therefore, supply chain management is even more important. Good supply chain management will help businesses have a competitive advantage and a foothold in the market. At the same time, they facilitate strategic expansion and better business development (Phan et al., 2020). Good goods supply chain management activities will ensure the input and output of goods. At the input, supply the right amount of goods, reduce inventory and reduce risks for businesses. At the output of the supply chain, the product is well managed, providing the necessary amount of product, bringing good revenue, reducing the risk of returning goods, and reducing inventory costs. In addition, good supply chain management also brings efficiency in logistics and logistics activities, bringing goods to businesses and customers quickly and on schedule, ensuring goods quality, optimizing costs and profits for the business. A perfect supply chain will help businesses have more advantages in business, maximize costs, and increase profits. Especially in the context of the globalized economy, businesses that decide to be selfsufficient and do everything themselves for business will not achieve the highest efficiency. Even being completely self- 
sufficient can cause a business to fall into the abyss because the costs are divided among many departments. Production capacity, technology and other factors are not taken into account (Swaminathan \& Tayur, 2003). Instead, the linkage between the units has their own strengths, and the smooth coordination between manufacturers - distributors - retailers. In each stage, subdividing will help suppliers reduce costs in the final product, and at the same time get the best quality product. Therefore, the role of supply chain management is extremely important (Nguyen et al. 2020).

\subsection{Supply chain finance}

Capital, Market, and Management are 3 issues affecting business operation and development. Lack of working capital is one of the problems that many business owners and leaders have headaches and try to solve but have no optimal solution, causing more than $50 \%$ of businesses to "break" in just a short time (Dubey et al., 2017). short time in operation. Supply chain financing is one of the essential elements to improve the competitiveness of supply chains in Vietnam. Supply chain financing services not only help suppliers and distributors increase working capital, but also enable them to do more book-keeping transactions, thus having the advantage of attracting global buyers' demand (Li et al., 2019). Supporting the release of working capital for parties involved in the supply chain is an activity that has been widely deployed in many countries around the world, especially in the developed world. rapidly in Europe, Asia and America. Transactional parties increasingly realize the outstanding benefits of SCF products, both in domestic and international payments (Nagati \& Rebolledo, 2013).

Financing is a recent emerging activity in emerging economies like Vietnam, especially applied to small and medium-sized enterprises to deal with financial pressures in the context of the current Covid-19 pandemic. Supply chain finance has significantly improved business performance and capital mobilization efficiency of small and medium-sized enterprises (Wuttke et al., 2019). In fact, when applying supply chain finance, small and medium-sized businesses can access capital faster and more efficiently, which ensures that the supply chain is not interrupted. Pfohl and Gomm (2009) argue that supply chain finance helps businesses have better financial ability and thereby improves the overall financial performance of the company. Li and Chen (2019) argue that supply chain finance helps to enhance resource assessment, minimize information management risks, thereby reducing cash cycle and improving firm performance. The supplier's commitment to the timing of funding and the amount of funding provided from the point of view of social exchange theory also explains the benefits of supply chain finance (Martin \& Hofmann, 2019). Although there have been many previous studies discussing the role and benefits of supply chain finance, there are still some issues that need to be considered for further research. Those previous studies mainly focused on the factors affecting the implementation and deployment of supply chain finance of small and medium-sized enterprises such as reducing risks in the supply chain, managing information networks (Xu et al., 2018). However, there is no research on the inherent attributes of a business that are its available resources that affect the ability to access and use supply chain finance. Meanwhile, corporate resources are the root of the problem of accessing supply chain finance. Therefore, in this study, we use resource theory to explain the impact mechanism of factors on supply chain finance.

\subsection{Resource dependence theory}

Resources play an important role in enabling businesses to realize and achieve their strategic and sustainable development goals (Ali et al., 2020). In order to have the necessary resources, which often have to be mobilized from outside, enterprises enter into formal and informal cooperation agreements with one or more other enterprises, in order to ensure a stable level of financial stability, quantity and quality of resources needed. However, this demand reduces the degree of autonomy of enterprises; in other words, make the business dependent on the environment and other businesses and the degree of dependence of each business is different depending on the particularities of the business involved. The essence of this dependence is the interdependence relationship between enterprises in the process of cooperation and resource exchange.

\subsection{Knowledge-Based View}

The business environment has changed dramatically over the past few decades. The role of traditional resources in enabling firms to gain competitive advantage has also changed. Science and technology development creates many opportunities as well as risks in efforts to find, build and maintain sustainable competitive advantages of enterprises. Businesses need to constantly adapt to the new business environment or make a breakthrough in changing the current environment. In addition to streamlining structure and processes to increase efficiency, businesses need to create new knowledge to increase creativity and breakthrough. Knowledge, which is difficult to imitate and highly complex, becomes the most important resource for the success of a business. Knowledge - Based View asserts that only new knowledge can be created, making a difference in knowledge and the ability to use knowledge to ensure a sustainable competitive advantage for businesses.

Knowledge consists of facts, information, descriptions, or skills acquired through experience or education. Knowledge can be formed from information or experiences or synthesized from them. Knowledge is the answer to the question "how", "why"; includes a reasonable way to collect and process information. The acquisition of knowledge depends on the perception of each person and the orientation of each business. 
An enterprise from the point of view of access to knowledge is a social community in which the expertise of individual and collective members is transformed into economically useful products/services through the application of organizational principles to manage orders more effectively. In the knowledge economy, business survival is based on the exchange of specialized knowledge and its use. Production requires the coordination of disparate knowledge, but in reality, it is difficult to do so due to the transferability of tacit knowledge as well as the risk of ownership of specific knowledge. Businesses exist because they are more efficient than the market in this activity. The ability of the enterprise lies in the organizational principles that structure relationships between individuals, groups or between organizations inside and outside the enterprise. Firms possess different information and expertise, and the difference has long-term effects on the performance of businesses, making them different. Applying good knowledge will help businesses stand firm and break through, creating a competitive advantage in the market. According to the KBV (Knowledge-based view) theory, knowledge is the most important resource of an enterprise. Knowledge creates a strong foundation on which businesses can create and sustain their competitive advantage. It contributes to the identification and implementation of strategies. All activities occurring in the enterprise require knowledge, which is the guiding guideline for all activities of the enterprise, from the organization (Phan et al. 2020; Song et al. 2013, 2016).

\subsection{SMES}

Small and medium enterprises (SMEs) are an important part of the private sector. In fact, SMEs have been present in most regions, localities, and these businesses have made good use of and exploited local resources. SMEs employ about half of the non-agricultural production workforce (accounting for 49\%) in the country and in some regions have employed most of the non-agricultural production workforce (Pham \& Phan, 2020). In addition to labor, SMEs also use the financial resources of the people in the area, the source of raw materials in the region for production and business. Although the number of SMEs is large, the size of small and micro enterprises accounts for a very large proportion, the number of medium-sized enterprises only accounts for $1.6 \%$ of the total number of SMEs. Because of its small scale, the operation of this business sector is facing many difficulties, especially when the Covid-19 epidemic outbreak and spread, specifically: Most SMEs exist and develop spontaneously and are small. According to economic experts, the strength of SMEs is quick and effective capital recovery; compact production organization and management apparatus; capable of penetrating into niche markets and non-profitable production and business fields. However, the Covid-19 pandemic has put the SME community in a difficult situation and many businesses are presently facing the risk of bankruptcy. Revenues of the SME sector have decreased, in which micro enterprises decreased the most, followed by small enterprises, medium enterprises and large enterprises. This reflects that the resilience of enterprises depends greatly on the size of enterprises. Businesses in the service sector have the most revenue reduction, followed by industry and construction. Enterprises in the agriculture, forestry and fishery sector have the least decrease in revenue (Le et al., 2019; Tran et al., 2020).

SMEs also face a shortage of input materials. Currently, micro-enterprises only have access to nearly $20 \%$ of the demand for raw materials and input materials. The domestic consumption market was also narrowed, with over two-thirds of enterprises saying that the domestic consumption market decreased sharply. The rate of enterprises facing difficulties due to the narrow export market is quite high. The decrease in export orders and difficulties in goods circulation are major difficulties for the majority of enterprises; Increased transportation and storage costs are also a concern. According to the size of enterprises, difficulty in goods circulation is the biggest problem for the group of micro enterprises; while for the SME group, the biggest difficulty is due to the decrease in export orders. Thus, with the financial potential and liquidity of the SME sector in our country still weak, when the Covid-19 pandemic spread and complicated developments, this business sector faced more and more difficulties in mobilizing resources. capital to develop production and business.

\section{Research method}

\subsection{Context and Sample}

According to a survey published in September 2019 by the Asian Development Bank (ADB), the gap in trade finance globally is now up to 1.5 trillion USD. Accordingly, $45 \%$ of loan applications of micro, small and medium enterprises were refused. This is a global challenge, inhibiting economic growth and directly affecting efforts to reduce poverty in countries. In Vietnam, businesses are also facing many difficulties in accessing supply chain financing products. In Vietnam, businesses that want to access bank capital often must have collateral (mainly real estate), while the form of unsecured loans in the supply chain is still underdeveloped. In addition, high interest rates also increase costs and product prices, making it difficult for businesses to compete in the market. Therefore, the problem of accessing financial resources is still a difficult problem for Vietnamese businesses today. The lack of working capital and transaction financing banking services such as supply chain financing has somewhat affected the ability to receive large orders or develop new relationships with partners in the value chain. treat. Without a supply chain financing solution, it is difficult for suppliers and distributors to optimize working capital management by converting receivables and inventory into cash and accessing credit with lower costs. In fact, SMEs face many difficulties in accessing working capital. Some surveys show that $70 \%$ of this group of businesses must use their own capital or borrow from informal sources at very high costs. The most common reason given today is that SMEs do not have much collateral, and loan documents do not meet the requirements of the Bank due to unclear management of books and financial statements. 
In Vietnam, supply chain support services have appeared, but have not yet made a clear mark. Service packages to support distributors are often implicitly understood as credit loans with strict conditions. However, until now, credit has hardly grown, forcing banks to specialize more in their products if they want to maintain growth momentum. It is possible to point to the cooperation model between Techcombank and Masan Consumer (Masan Consumer). Techcombank is known as a bank with strengths in the retail sector and always strives to be at the forefront of specializing in products for each target audience, while Masan Consumer is the leading company in operations in the fast-moving consumer goods sector. In this supply chain financial product, the target audience is the distributor group of Masan Consumer, which is quite large with fast-moving consumer goods products dominating the market such as instant noodles, soy sauce, or coffee, mineral water. From the strategic partnership with Masan, Techcombank provides capital for agents and distributors of Masan's goods. Customers can overdraft their account to pay for goods to Masan (the overdraft limit depends on the customer's financial ability). A special feature here is that the bank knows this supply chain well, so the loan period is flexible to match the customer's capital need cycle, not a fixed term of 3 or 6 months. The advantage is that distributors only need $25 \%$ to $40 \%$ of their own capital to trade in the products that Masan Consumer produces. Techcombank also accepts up to $100 \%$ of goods as collateral, and the loanto-real estate appraisal ratio is up to $90 \%$, at the same time, the procedures are simplified, and the loan interest rate is reasonable. In fact, this model has been introduced since 2010. Techcombank also cooperates with many other companies in the supply chain financing model, such as with HTC, or Vingroup with purchasing agency financing. and sponsor individual customers to buy for use. This model is like a kind of niche market. It is niche, but the combination with a leading company in each field, such as Masan's dominance in FMCG, will bring a huge potential market for Techcombank. Vietnam's economy is changing rapidly, reflected in increasingly extensive and sophisticated supply chains. Each business only plays a certain role in that supply chain. For banks, the development of financing activities for the supply chain also promotes economic growth, like credit activities. In addition to Techcombank, several credit institutions in Vietnam, including Sacombank, have strongly deployed closed-chain financing solution packages from distributors, agents to suppliers and suppliers of many enterprises. has famous brands and distribution channels spread on a large scale in the territory of Vietnam. With a uniform preferential policy throughout the Sacombank system, distributors and agents of enterprises will enjoy outstanding incentives including incentives on account transaction fees, guarantee fees, loan interest rates and interest rates. especially, the rate of financing for collateral that is real estate can be up to $100 \%$ of the property's value. With this solution package, distributors and agents of businesses can access Sacombank's quick and timely loan with a lower lending interest rate of 1\% - 2\%/year than ordinary customers. thereby proactively source of business capital, saving transaction costs and time; while businesses increase sales at low costs, proactively plan their finances, reduce management costs for receivables and above all, share payment risks with the Bank.

To test the research hypotheses, we conducted a survey on 1000 small and medium enterprises using supply chain finance of commercial banks. The list of small and medium enterprises we collect from the corporate credit department of commercial banks. After that, we conduct direct interviews and surveys when we have agreed on research variables and research models, we proceed to send questionnaires directly and online via email. After 3 months of continuously calling and urging us to collect 892 survey questionnaires. Then, we proceed to enter data and filter out invalid survey questionnaires. The remaining results are 856 votes representing 856 SMEs of Vietnam across the country.

\subsection{Research model}

Fig. 1 presents the structure of the proposed method.

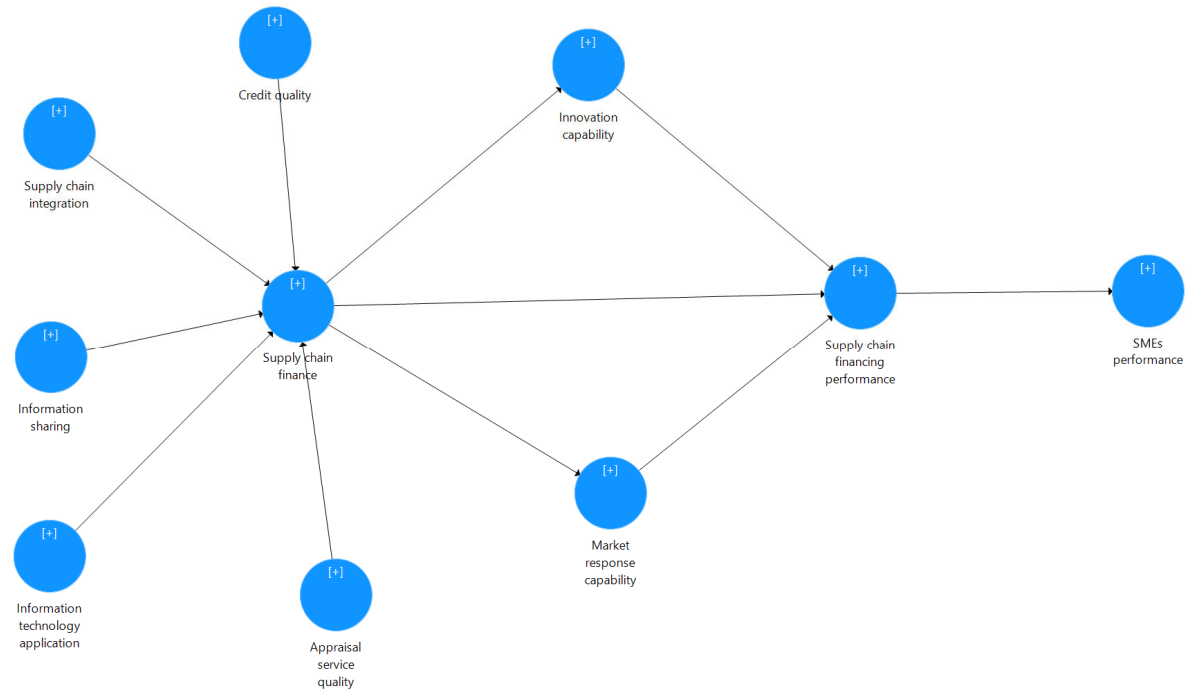

Fig. 2. Research model 
Research model of factors affecting supply chain finance. At the same time, evaluate the influence of supply chain finance on supply chain financing performance through two intermediate variables, innovation capability and market response capability. Finally, we look at SME performance. The scales of the research variables were developed from previous studies and adjusted to suit the context of SMEs in Vietnam and commercial banks in Vietnam. All scales are measured by the perception of SMEs through a 5-point Likert scale with 1 being completely disagree and 5 being completely agree. As follows:

Innovation Capability (IC) (Narasimhan \& Das, 1999; Tomlinson, 2011)

IC1: Launching new products and technologies in a short time at low cost

IC2: Always improve existing products and business processes in a timely manner

IC3: Continually introduce new methods or technologies into business management processes

IC4: Continually introduce new materials and technologies in production and R\&D

IC5: Implement organizational changes and improvements as required by production or sales

Market responsiveness (MRC) (Garrett et al., 2009; Chang et al., 2013)

$\mathrm{MRC1}$ : Can change products to meet customer needs quickly

MRC2: Continuously promoting new products to the market

MRC3: Provide new products to downstream customers at a lower cost

MRC4: Campaign to offer new, flexible and changeable products

MRC5: Can flexibly respond to changes in market demand

Supply chain finance (Camerinelli, 2009; Caniato et al., 2016; Ali et al. 2020)

SCF1: Get funding from real estate or movable based supply chain partners

SCF2: Get funding from supply chain partners based on accounts receivable,

SCF3: Get funding from supply chain partners based on accounts payable

SCF4: Solve financial problems by partnering with supply chain partners

Supply Chain Financing Performance (SCFP) (Gomm, 2010; Tagoe et al., 2005; Song \& Wang, 2013)

SCFP1: Financing interest rate is reasonable

SCFP2: Flexible Funding Volume

SCFP3: Flexible funding period

SCFP4: Supply Chain Financing as a Hedging System

SCFP5: Supply chain financing increases the coordination of capital flows in the supply chain.

SCFP6: Supply Chain Financing delivers a high level of overall supply chain efficiency.

Supply Chain Integration (SCI) (Frohlich \& Westbrook, 2001; Flynn et al., 2010; Phan et al. 2020)

SCI1: Actively interact with suppliers and discuss product development

SCI2: Are there procedures or methods for obtaining supplier performance information

SCI3: Actively interact with customers to improve product or service quality

SCI4: Have formal practices and standard operating procedures for communicating with customers and suppliers, and strive to establish long-term cooperative relationships

Application of information technology (ITA) (Subramani, 2004)

IT1: Connecting different functional departments through computer network

IT2: Using information technology to integrate internal resources

IT3: Using information technology to share resources with business partners

IT4: Using information technology to access resources of heterogeneous organizations in a global network

IT5: Using information technology to support business processes, such as orders, procurement, shipping, inventory, sales, and distribution

Credit Quality (CQ) (Tagoe et al., 2005; Gomm, 2010)

FQ1: Good liquidity and working capital of the company

FQ2: Commercial banks' interest rates are reasonable

FQ3: Flexible commercial banks' lending volume

FQ4: Flexible commercial banks' lending time

Information Sharing (IS) (Baihaqi \& Sohal, 2013; Lee \& Whang, 2000; Yu et al., 2001)

Commercial banks can access information of enterprises in the following ways:

IC1: From your main suppliers

IC2: From your other alternative suppliers

IC3: From key customers of the business

IC4: From your other alternative customers

IC5: From corporate agents and other organizations

\subsection{Analytical techniques}

We use Excel 2020 software for initial data entry. Then, we used SPSS 23 software to test the reliability of the scale, analyze EFA - exploratory factor analysis. When the scale factors satisfy the reliability moderation, we use SmartPLS 3.3.6 software to test CFA - confirmatory factor analysis to test the overall reliability, discriminant validity, test the indicators of the measurement model and finally evaluate the structural model to test the research hypotheses.

According to Hair et al (2011), the number of studies using PLS-SEM published in recent years has increased rapidly. In the fields of organizational behavior, information system management, strategic management and in marketing research because 
PLS-SEM has many advantages over CB-SEM in the following situations: (1) Acceptance small sample size, data not normally distributed; (2) Can be used for complex research models with many intermediate, regulatory, latent and observed variables. Especially the structural model; (3) Capable of analyzing the structure of the result model (Reflective) and the cause model (Formative); (4) Suitable for predictive-oriented studies (Henseler et al., 2015).

In addition, if non-normally distributed data are a big problem for CB-SEM (ie: CB-SEM requires normally distributed data, this is said to be very difficult since studies are often surveyed by non-probability convenience methods). However, PLSSEM is "very powerful" when using non-normally distributed data (Hair et al., 2014).

According to Hair et al (2014), Chin (2010) when using PLS-SEM technique, it is necessary to verify through 2 steps: (1) Check the measurement model; and (2) Verify the structural model. As follows:

(1) Evaluation of the measurement model:

- Reliability of indicator variables (or called observed variables)

In the outcome model (Reflective model), the indicator variables are explained by the latent variable, the load factor of the indicator variables $>=0.7$ (or 0.40 is acceptable in exploratory studies (Hair et al., 2014).

- Intrinsically consistent reliability

Intrinsically consistent reliability is measured through Cronbach's alpha value (Henseler et al., 2015) with an acceptable value of 0.7 in the initial research periods and each latent variable must have at least 2 indicator variable.

- Convergence value

Convergence value evaluates the relationship between indicators measuring the same latent variable. The convergence value of the scale is evaluated through:

* For exploratory studies, the composite confidence coefficient (CR) is in the range of $0.6-0.7$, but ideally should be $\geq 0.7$;

* The external load coefficient of the observed variables must be $\geq 0.708$;

* Average variance extracted AVE (Average variance extracted, reflecting the overall variability of observed variables calculated by latent variables) must be $\geq 0.5(0.7082=0.5)$ (Henseler et al., 2015); and Coefficient rho $\mathrm{A}>0.7$.

Discriminant validity measures discriminant validity to help ensure that there is no correlation between the factors used to measure the factors. Discriminant value is an important criterion in measurement model analysis. It measures the distinction between concepts in the research model (Henseler et al., 2015). There are two levels when considering discriminant validity, which are:

* The degree of distinction between components in the same concept (within construct, if it is a concept of level 2 or higher); * The degree of cross-construction between different concepts, or it refers to the critical measurement model (saturated model, the concepts in the research model are free to relate to each other).

The discriminant value is said to be eligible while the value of the criterion HTMT (heterotrait - monotrait) $<0.85$ (Henseler et al., 2015) or using the square root AVE of each measure is larger than the system. Latent variable correlations between that factor and other factors.

In addition, in evaluating the measurement model, it is necessary to evaluate the multicollinearity of the indicator variables (VIF value $<5$, no multicollinearity). Henseler et al (2015) said that, to be able to conclude that the model fits the market data (goodness of model fit), the following coefficients need to be satisfied:

* Coefficient SRMR (standardized root mean square residual) $<0.082$ (if the exploratory research type can accept $<0.12$ );

* Coefficient d_ULS $<95 \%$;

* Coefficient d_G $1<95 \%$;

* Coefficient d_ $\mathrm{G} 2<95 \%$

(2) Evaluation of structural model

The second step in PLS-SEM analysis is to evaluate the structural model through Bootstrapping method with sample size of 5000 (return-sampling). According to Hair et al. (2017) proposed indicators in the evaluation of structural models include:

1) The coefficient of determining the variation of the model $\left(R^{2}\right)$,

2) Degree (intensity) of influence $\left(\mathrm{f}^{2}\right)$

3) The influence factor $(ß)$ includes t values and confidence intervals,

- The coefficient of determination of the model's variation (Coefficient of determination, $\mathrm{R}^{2}$ )

The $\mathrm{R}^{2}$ value is defined as the percentage of variation in endogenous variables that is explained by exogenous variables (Hair et al. 2021). The $\mathrm{R}^{2}$ value ranges from 0 to 1 . The closer $\mathrm{R}^{2}$ is to 1 , the better the model fits the dataset. The closer $\mathrm{R}^{2}$ is to 0 , the less suitable the model is. Therefore, $\mathrm{R}^{2}$ results are important indicators of the relationship between latent variables in the model and are the main criteria for evaluating structural models (Hair et al., 2021).

Henseler et al. (2015) show that the acceptable level of ${ }^{2}$ depends on the research context. However, the rating is still given for reference respectively: strong (0.67), moderate (0.33) and weak (0.19).

- Degree of influence (Effect size, $\mathrm{f}^{2}$ )

Also according to Henseler et al (2015) to consider the impact of exogenous variables on endogenous variables, it is necessary to evaluate the influence coefficient $\mathrm{f} 2$. When $\mathrm{f} 2$ is at 0.02 levels; 0.15 and 0.35 , it can be concluded that the impact level is weak, fair and strong, respectively.

- Path coefficient estimates

The coefficient of influence (ß) provides information about the strength of the relationship between exogenous and endogenous variables. The value of $\beta$ also indicates the directional relationship (positive or negative) of the concept in the research model (Henseler et al., 2015), corresponding to the tested hypothesis. To determine the significance of the relationship, the Bootstrapping approach is proposed (Hair et al. 2014). 
The Bootstrapping method uses resampled sampling $(n=5000)$ to estimate the accuracy of the PLS estimates by replacing sampling from the original data set (Hair et al. 2014). The results of the t-statistic can be used to determine the significance level ( $p$-value). Accordingly, the statistical value $t=1.6497$ corresponds to the $90 \%$ confidence level; $t=1.9676$ corresponds to $95 \%$ confidence and $t=2.5916$ corresponds to $99 \%$ confidence.

\section{Result}

The results of testing the reliability of the original scale on SPSS23 software show that the innovation capacity variables are 4; Market responsiveness 3; Information technology 1 and information technology 4 have the Cronbach Alpha coefficient less than 0.7 and the total variable correlation coefficient less than 0.4. Therefore, we remove those scales from the research model. After removing invalid scales from the research model, the test results of EFA discovery factors are satisfied to perform the next tests in Smart PLS 3.3.6. The following results:

Table 1

Construct Reliability and Validity

\begin{tabular}{lcccc}
\hline & Cronbach's Alpha & rho_A & Composite Reliability & Average Variance Extracted (AVE) \\
\hline Appraisal service quality & 0.928 & 0.928 & 0.928 & 0.910 \\
Credit quality & 0.910 & 0.911 & 0.681 & 0.698 \\
Information sharing & 0.898 & 0.898 & 0.872 & 0.638 \\
Information technology application & 0.872 & 0.873 & 0.920 & 0.945 \\
Innovation capability & 0.920 & 0.920 & 0.925 & 0.967 \\
Market response capability & 0.945 & 0.945 & 0.939 & 0.947 \\
SMEs performance & 0.923 & 0.971 & 0.907 \\
Supply chain finance & 0.957 & 0.949 & 0.987 \\
Supply chain financing performance & 0.947 & 0.887 & 0.645 \\
Supply chain integration & 0.887 & & 0.662 \\
\hline
\end{tabular}

The results show that all pre-hidden variables in the research model have Cronbach Alpha coefficients greater than 0.8 which is very good and AVE coefficients are also greater than 0.5 , ensuring reliability and value for latent variables. hidden (Hair et al., 2011, 2014, 2017; Henseler et al., 2009, 2015).

Table 2

Discriminant Validity (Fornell-Larcker Criterion)

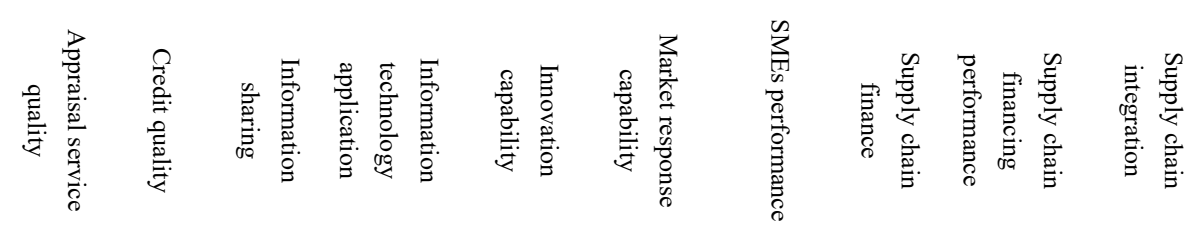

\begin{tabular}{|c|c|c|c|c|c|c|c|c|c|c|}
\hline Appraisal service quality & 0.825 & & & & & & & & & \\
\hline Credit quality & 0.030 & 0.793 & & & & & & & & \\
\hline Information sharing & 0.026 & 0.049 & 0.799 & & & & & & & \\
\hline Information technology application & 0.295 & 0.036 & 0.022 & 0.833 & & & & & & \\
\hline Innovation capability & 0.461 & 0.474 & 0.470 & 0.431 & 0.835 & & & & & \\
\hline Market response capability & 0.204 & 0.171 & 0.193 & 0.169 & 0.237 & 0.880 & & & & \\
\hline SMEs performance & 0.511 & 0.462 & 0.526 & 0.465 & 0.487 & 0.284 & 0.898 & & & \\
\hline Supply chain finance & 0.398 & 0.040 & 0.041 & 0.015 & 0.467 & 0.168 & 0.478 & 0.771 & & \\
\hline Supply chain financing performance & 0.333 & 0.327 & 0.368 & 0.316 & 0.538 & 0.381 & 0.418 & 0.332 & 0.803 & \\
\hline Supply chain integration & 0.186 & 0.025 & 0.009 & 0.271 & 0.454 & 0.146 & 0.467 & 0.031 & 0.313 & 0.813 \\
\hline
\end{tabular}

The test results show that the values above the diagonal (in bold) are larger than all the values outside the diagonal. The smallest value on the diagonal of 0.771 is still larger than the maximum value off the diagonal of 0.526 . Thus, according to Hair et al. $(2009,2011,2014,2017)$ and Henseler et al. $(2009,2015)$, the research variables ensure discriminant validity. Satisfied to perform testing of research hypotheses. The R-square results show that the research variables are explained quite well. Specifically, the research variables in the model explain nearly $60 \%$ of the variation of Supply chain financing performance and nearly $50 \%$ of the variation of supply chain finance.

F-square: The F-square values of the research variables all ensure the level of association and impact at an average level or higher. With the minimum value is 0.201 and the maximum is 0.389 .

Model fit: The results of the fit test of the research model show that the NFI values are all greater than 0.85 and the other values are satisfied as suggested by Hair et al. $(2011,2014,2017)$ and Henseler et al. $(2009,2015)$.

The result of the PLS coefficient is given in Fig. 3. 
Table 3

\begin{tabular}{lcc}
\hline & R Square & R Square Adjusted \\
\hline Innovation capability & 0.218 & 0.216 \\
Market response capability & 0.228 & 0.226 \\
SMEs performance & 0.375 & 0.373 \\
Supply chain finance & 0.481 & 0.483 \\
Supply chain financing performance & 0.563 & 0.558 \\
\hline
\end{tabular}

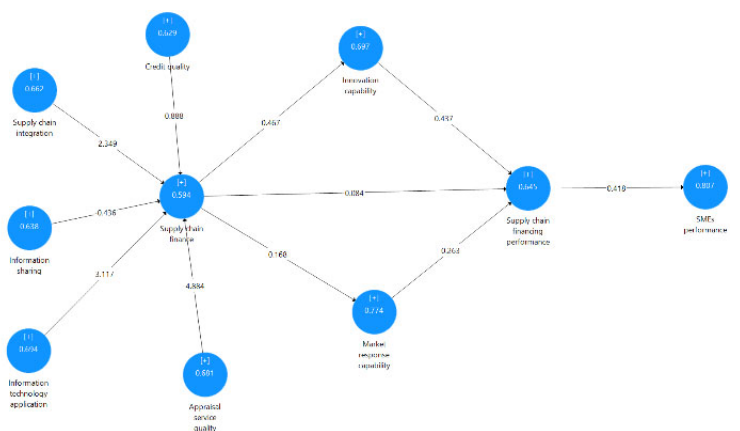

Fig. 3. AVE coefficients in construction and path coefficients

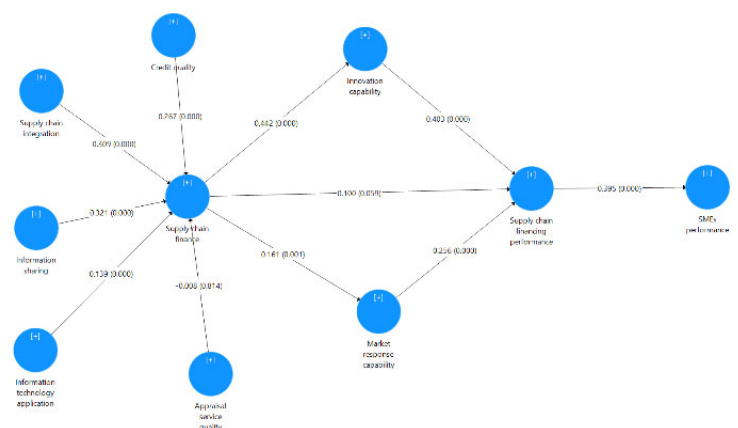

Fig. 4. Result of hypothesis testing (Bootstrapping)

Thus, the process of testing the measurement model gives satisfactory results. Next, we conduct structural model testing, to test the research hypotheses. The overall SEM model test results are given in Fig. 4 . The results in Fig. 4 show that all factors affecting supply chain finance are statistically significant except for the variable Appraisal service quality, which has no statistically significant impact on supply chain finance. In the context of Vietnam - an emerging, transitional economy valuation services have not been implemented consistently, providing effective and timely information, but are just activities on the list. In other words,

Credit quality has a statistically significant positive effect on supply chain finance at a fairly strong level of 0.267 at $1 \%$ significance level $\left(P_{-}\right.$value $\left.=0.000\right)$.

Supply chain integration has a statistically significant positive effect on supply chain finance at a very strong level of 0.309 at $1 \%$ significance level $\left(\mathrm{P}_{-}\right.$value $\left.=0.000\right)$.

Information sharing has a statistically significant positive effect on supply chain finance at the very strong level of 0.321 at the $1 \%$ significance level $(\mathrm{P}$ value $=0.000)$

Information technology application has a statistically significant positive effect on supply chain finance at the mean level of 0.139 at $1 \%$ significance level $(P$ value $=0.000)$.

Supply chain finance has a very strong positive impact on Innovation capability at an impact level of 0.442 with a significance level of $1 \%\left(P_{-}\right.$value $\left.=0.000\right)$.

Supply chain finance has a moderate positive impact on the Market response capability at an impact level of 0.161 with a significance level of $1 \%\left(\mathrm{P}_{-}\right.$value $\left.=0.001\right)$.

Innovation capability has a very strong positive effect on supply chain financing performance with an impact factor of 0.403 at $1 \%$ significance level $\left(P_{\text {_value }}=0.000\right)$.

The market response capability also positively affects supply chain financing performance at an impact level of 0.256 at the $1 \%$ significance level $\left(\mathrm{P}_{-}\right.$value $\left.=0.000\right)$.

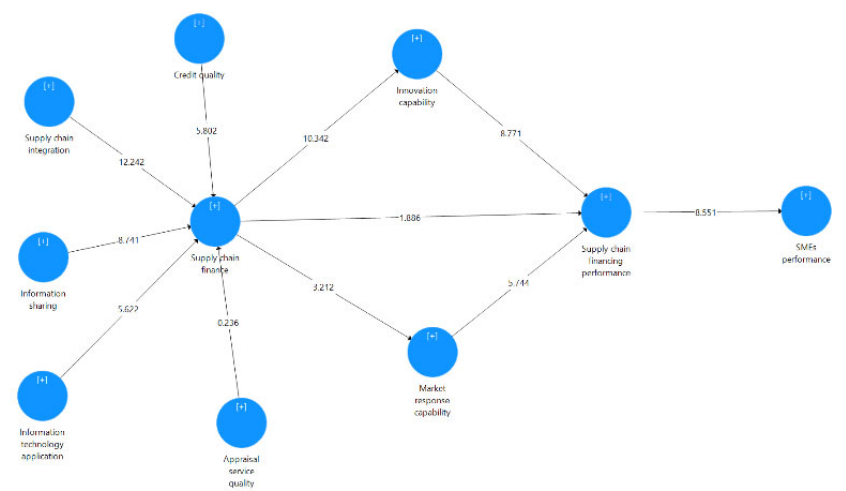

Fig. 5. Result T-value 
In the overall SEM model shown in Fig. 2, Supply chain finance no longer has a statistically significant effect on supply chain financing performance. The study will discuss the mediating role of the two mediating variables in the following section. Finally, Supply chain financing performance has strong, positive effects on SME performance with an impact factor of 0.395 at $1 \%$ significance level $\left(\mathrm{P}_{\text {_value }}=0.000\right)$. The results of the T-value summary are given in Fig. 5. From the results in Fig. 4 and the above analysis, it is shown that credit quality, supply chain integration, information sharing in the supply chain and information technology capabilities of SMEs in Vietnam are factors critical to the success of your access to supply chain financing. For businesses with good credit quality, combined with being a link in the global supply chain, the ability to access working capital and supply chain financing is very high. And then, the business activities of the enterprise will ensure the principle of continuity, not be interrupted and ensure the sustainable development of the business even during the current Covid-19 pandemic. At the same time, the results of the research data test once again confirm the great role and benefits of supply chain finance in supporting the development of SMEs in Vietnam. Supply chain finance is an important foundation to ensure and improve SME performance. The results of testing the research hypotheses are summarized as follows:

Table 4

Path Coefficients (Mean, STDEV, T-Values, P-Values)

\begin{tabular}{|c|c|c|c|c|c|}
\hline & $\begin{array}{c}\text { Original } \\
\text { Sample }(\mathrm{O})\end{array}$ & $\begin{array}{c}\text { Sample } \\
\text { Mean } \\
\text { (M) }\end{array}$ & $\begin{array}{l}\text { Standard } \\
\text { Deviation } \\
\text { (STDEV) }\end{array}$ & $\begin{array}{c}\text { T Statistics } \\
(|\mathrm{O} / \mathrm{STDEV}|)\end{array}$ & P Values \\
\hline Appraisal service quality $\rightarrow$ Supply chain finance & -0.008 & 0.001 & 0.032 & 0.236 & 0.814 \\
\hline Credit quality $\rightarrow$ Supply chain finance & 0.267 & 0.257 & 0.046 & 5.802 & 0.000 \\
\hline Information sharing $\rightarrow$ Supply chain finance & 0.321 & 0.326 & 0.037 & 8.741 & 0.000 \\
\hline Information technology application $\rightarrow$ Supply chain finance & 0.139 & 0.142 & 0.025 & 5.622 & 0.000 \\
\hline Innovation capability $\rightarrow$ Supply chain financing performance & 0.403 & 0.403 & 0.046 & 8.771 & 0.000 \\
\hline Market response capability $\rightarrow$ Supply chain financing performance & 0.256 & 0.257 & 0.045 & 5.744 & 0.000 \\
\hline Supply chain finance $\rightarrow$ Innovation capability & 0.442 & 0.444 & 0.043 & 10.342 & 0.000 \\
\hline Supply chain finance $\rightarrow$ Market response capability & 0.161 & 0.162 & 0.050 & 3.212 & 0.001 \\
\hline Supply chain finance $\rightarrow$ Supply chain financing performance & 0.100 & 0.101 & 0.053 & 1.886 & 0.059 \\
\hline Supply chain financing performance $\rightarrow$ SMEs performance & 0.395 & 0.396 & 0.046 & 8.551 & 0.000 \\
\hline Supply chain integration $\rightarrow$ Supply chain finance & 0.309 & 0.304 & 0.025 & 12.242 & 0.000 \\
\hline
\end{tabular}

The results showed that only 2 hypotheses were rejected, the rest all hypotheses were supported.

Table 5

Confidence Intervals

\begin{tabular}{lccc}
\hline & Original Sample $(\mathrm{O})$ & Sample Mean $(\mathrm{M})$ & $2.5 \%$ \\
\hline Appraisal service quality $\rightarrow$ Supply chain finance & -0.008 & 0.001 & -0.061 \\
Credit quality $\rightarrow$ Supply chain finance & 0.267 & 0.257 & 0.161 \\
Information sharing $\rightarrow$ Supply chain finance & 0.321 & 0.326 & 0.257 \\
Information technology application $\rightarrow$ Supply chain finance & 0.139 & 0.142 & 0.093 \\
Innovation capability $\rightarrow$ Supply chain financing performance & 0.403 & 0.403 & 0.313 \\
Market response capability $\rightarrow$ Supply chain financing performance & 0.256 & 0.257 & 0.167 \\
Supply chain finance $\rightarrow$ Innovation capability & 0.442 & 0.444 & 0.357 \\
Supply chain finance $\rightarrow$ Market response capability & 0.161 & 0.162 & 0.060 \\
Supply chain finance $\rightarrow$ Supply chain financing performance & 0.100 & 0.101 & -0.004 \\
Supply chain financing performance $\rightarrow$ SMEs performance & 0.395 & 0.396 & 0.325 \\
Supply chain integration $\rightarrow$ Supply chain finance & 0.309 & 0.304 & 0.2404 \\
\hline
\end{tabular}

\section{Table 6}

Confidence Intervals Bias Corrected

\begin{tabular}{|c|c|c|c|c|c|}
\hline & Original Sample $(\mathrm{O})$ & Sample Mean (M) & Bias & $2.5 \%$ & $97.5 \%$ \\
\hline Appraisal service quality $\rightarrow$ Supply chain finance & -0.008 & 0.001 & 0.008 & -0.075 & 0.049 \\
\hline Credit quality $\rightarrow$ Supply chain finance & 0.267 & 0.257 & -0.010 & 0.173 & 0.347 \\
\hline Information sharing $\rightarrow$ Supply chain finance & 0.321 & 0.326 & 0.004 & 0.251 & 0.391 \\
\hline Information technology application $\rightarrow$ Supply chain finance & 0.139 & 0.142 & 0.003 & 0.086 & 0.184 \\
\hline Innovation capability $\rightarrow$ Supply chain financing performance & 0.403 & 0.403 & 0.001 & 0.312 & 0.491 \\
\hline Market response capability $\rightarrow$ Supply chain financing performance & 0.256 & 0.257 & 0.001 & 0.163 & 0.338 \\
\hline Supply chain finance $\rightarrow$ Innovation capability & 0.442 & 0.444 & 0.002 & 0.349 & 0.517 \\
\hline Supply chain finance $\rightarrow$ Market response capability & 0.161 & 0.162 & 0.001 & 0.055 & 0.253 \\
\hline Supply chain finance $\rightarrow$ Supply chain financing performance & 0.100 & 0.101 & 0.001 & -0.008 & 0.200 \\
\hline Supply chain financing performance $\rightarrow$ SMEs performance & 0.395 & 0.396 & 0.002 & 0.300 & 0.480 \\
\hline Supply chain integration $\rightarrow$ Supply chain finance & 0.309 & 0.304 & -0.006 & 0.253 & 0.349 \\
\hline
\end{tabular}

To test in more detail the impact of supply chain finance factors, we test the factors according to the following model: 


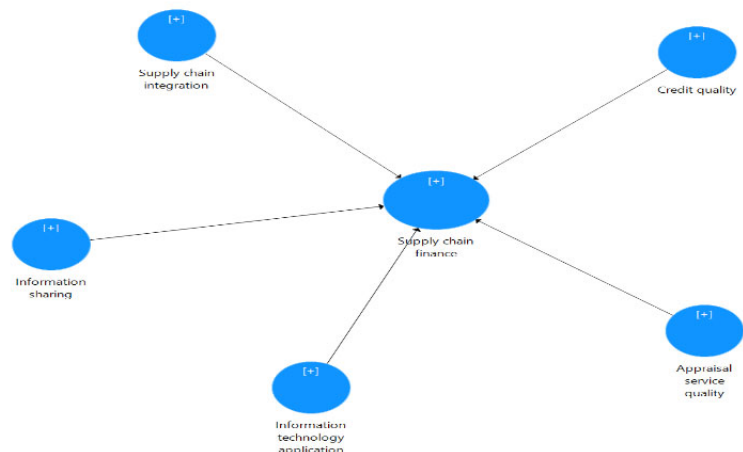

Fig. 6. Factors affecting supply chain finance

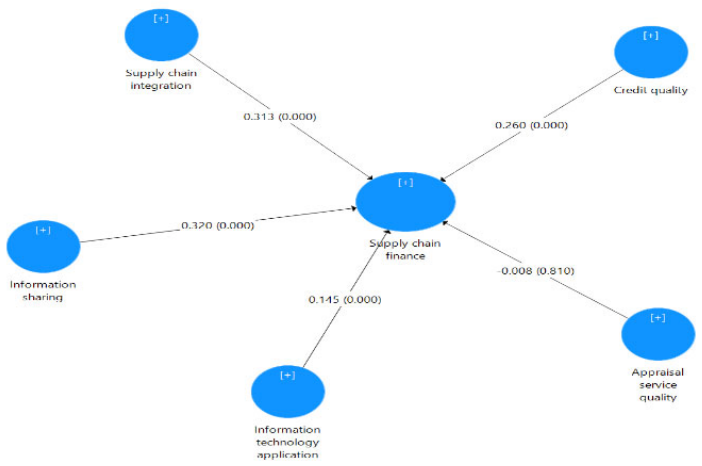

Fig.7. Results of separate test of factors affecting supply chain finance

The results show that all four factors of credit quality, supply chain integration, information sharing and information technology simultaneously constitute supply chain finance at the $1 \%$ significance level $\left(P_{-}\right.$value $\left.=0.000\right)$ at the impact level. moving is 0.260 , respectively; 0.313; 0.320 and 0.145. In the overall SEM model in Fig. 2 or in the results in Fig. 4, valuation service quality still has no statistical significance to supply chain finance. According to resource-based theory and resourcedependent theory, supply chain finance activities will directly support SMEs performance. Therefore, we test the role of supply chain finance on SME performance with the following model and results:

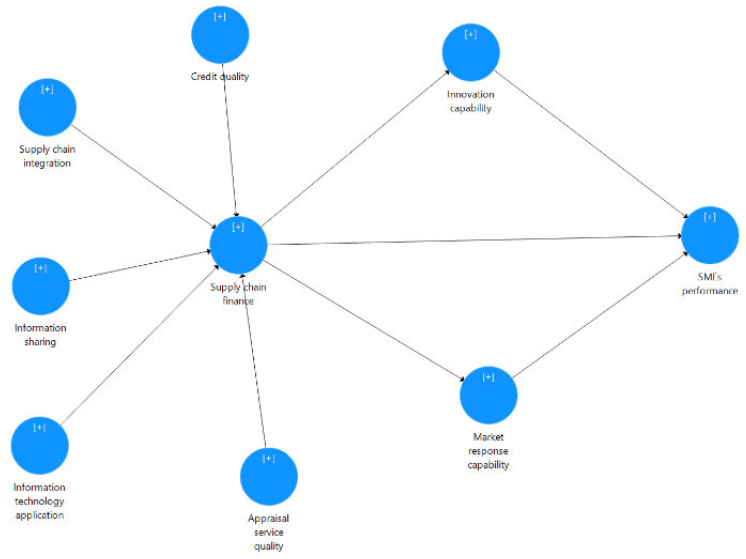

Fig. 8. Role of supply chain finance vs SMEs performance

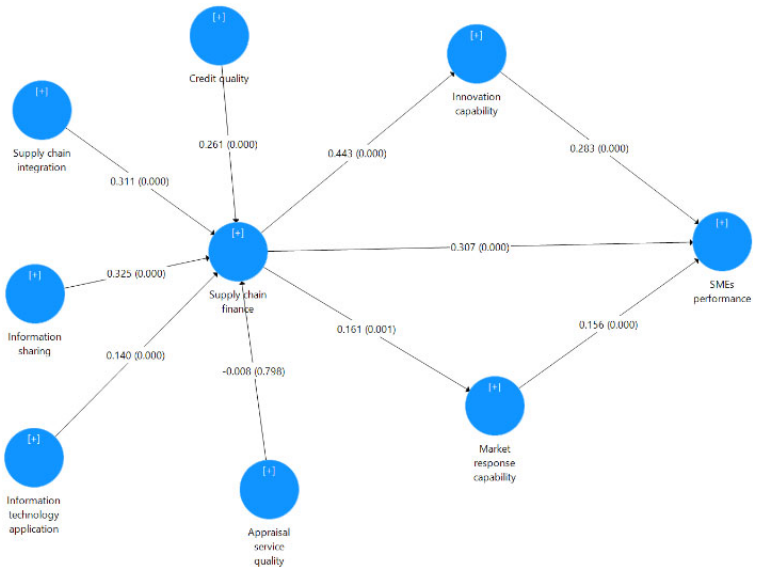

Fig. 9. Results of testing the role of supply chain finance with SMEs performance

The results show that, unlike supply chain financing performance, supply chain finance still has a direct statistically significant impact on SMEs performance with a strong impact factor at 0.307 at $1 \%$ significance level $\left(P_{-}\right.$value $\left.=0.000\right)$ in the SEM model in Figure 6. It means that the variables innovation capability and market response capability do not play an intermediary role in the relationship between supply chain finance and SME performance in small and medium enterprises in Vietnam at present. Both the Innovation capability and Market response capability variables have a statistically significant impact on SMEs performance with the impact coefficients of 0.283 and 0.156 respectively and at the $1 \%$ significance level $\left(\mathrm{P} \_\right.$value $=$ 0.000). The summary results of the research hypotheses of the model considering SME performance are as follows:

Table 8

Path Coefficients (Model 3) (Mean, STDEV, T-Values, P-Values)

\begin{tabular}{|c|c|c|c|c|c|}
\hline & $\begin{array}{c}\text { Original } \\
\text { Sample (O) }\end{array}$ & $\begin{array}{c}\text { Sample } \\
\text { Mean (M) }\end{array}$ & $\begin{array}{c}\text { Standard } \\
\text { Deviation } \\
\text { (STDEV) }\end{array}$ & $\begin{array}{c}\text { T Statistics } \\
(|\mathrm{O} / \mathrm{STDEV}|)\end{array}$ & $\begin{array}{c}\mathrm{P} \\
\text { Values }\end{array}$ \\
\hline Appraisal service quality $\rightarrow$ Supply chain finance & -0.008 & 0 & 0.032 & 0.256 & 0.798 \\
\hline Credit quality $\rightarrow$ Supply chain finance & 0.261 & 0.252 & 0.044 & 5.899 & 0 \\
\hline Information sharing $\rightarrow$ Supply chain finance & 0.325 & 0.329 & 0.036 & 9.035 & 0 \\
\hline Information technology application $\rightarrow$ Supply chain finance & 0.14 & 0.144 & 0.024 & 5.825 & 0 \\
\hline Innovation capability $\rightarrow$ SMEs performance & 0.283 & 0.282 & 0.06 & 4.678 & 0 \\
\hline Market response capability $\rightarrow$ SMEs performance & 0.156 & 0.154 & 0.042 & 3.753 & 0 \\
\hline Supply chain finance $\rightarrow$ Innovation capability & 0.443 & 0.444 & 0.042 & 10.462 & 0 \\
\hline Supply chain finance $\rightarrow$ Market response capability & 0.161 & 0.163 & 0.05 & 3.233 & 0.001 \\
\hline Supply chain finance $\rightarrow$ SMEs performance & 0.307 & 0.31 & 0.055 & 5.628 & 0 \\
\hline Supply chain integration $\rightarrow$ Supply chain finance & 0.311 & 0.305 & 0.024 & 12.724 & 0 \\
\hline
\end{tabular}


Finally, we examine the mediating role of the Market response capability and Innovation capability in the relationship between supply chain finance and supply chain financing performance. Test procedure according to Hair et al. (2014) as follows:

Step 1: Direct impact test

Step 2: Evaluate through the test results in the overall SEM model.

The results of the direct impact test are shown through the model and the test results are as follows:

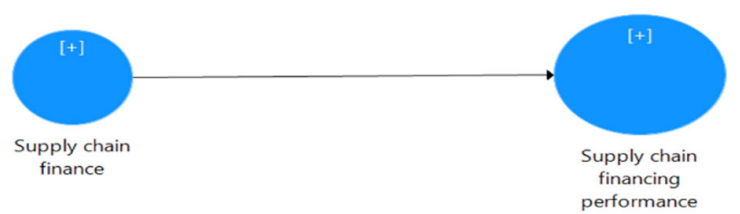

Fig.10. Direct impact test

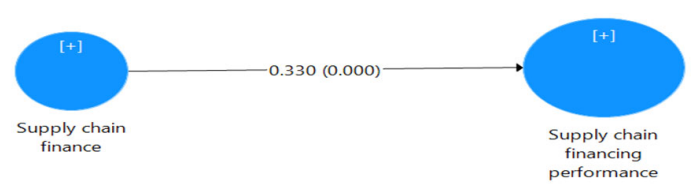

Fig.11. Direct impact test results

From the results in Fig. 9 it is shown that when considering the direct effect supply chain finance has a direct statistically significant impact on supply chain financing performance, but in the overall SEM model supply chain finance no longer has a significant effect. statistically significant to supply chain financing performance as well. This means that according to Hair et al. (2014), two intermediate variables, Innovation capability and Market response capability, have a full mediating role in this relationship. Summarizing all the effects of research variables in the research model is as follows:

Table 10

Total Indirect Effects

\begin{tabular}{|c|c|c|c|c|c|}
\hline & $\begin{array}{c}\text { Original } \\
\text { Sample } \\
(\mathrm{O})\end{array}$ & $\begin{array}{c}\text { Sample } \\
\text { Mean } \\
(\mathrm{M})\end{array}$ & $\begin{array}{c}\text { Standard } \\
\text { Deviation } \\
\text { (STDEV) }\end{array}$ & $\begin{array}{l}\text { T Statistics } \\
(|\mathrm{O} / \mathrm{STDEV}|)\end{array}$ & P Values \\
\hline Appraisal service quality $\rightarrow$ Innovation capability & -0.004 & 0.000 & 0.014 & 0.254 & 0.8 \\
\hline Appraisal service quality $\rightarrow$ Market response capability & -0.001 & 0.000 & 0.006 & 0.241 & 0.81 \\
\hline Appraisal service quality $\rightarrow$ SMEs performance & -0.004 & 0.000 & 0.015 & 0.252 & 0.801 \\
\hline Appraisal service quality $\rightarrow$ Supply chain finance & 0.000 & 0.000 & 0.000 & 0.000 & 0.000 \\
\hline Credit quality $\rightarrow$ Innovation capability & 0.116 & 0.112 & 0.023 & 5.025 & 0.000 \\
\hline Credit quality $\rightarrow$ Market response capability & 0.042 & 0.041 & 0.014 & 3.009 & 0.003 \\
\hline Credit quality $\rightarrow$ SMEs performance & 0.12 & 0.115 & 0.021 & 5.581 & 0.000 \\
\hline Credit quality $\rightarrow$ Supply chain finance & 0.000 & 0.000 & 0.000 & 0.000 & 0.000 \\
\hline Information sharing $\rightarrow$ Innovation capability & 0.144 & 0.146 & 0.02 & 7.033 & 0.000 \\
\hline Information sharing $\rightarrow$ Market response capability & 0.052 & 0.054 & 0.018 & 2.876 & 0.004 \\
\hline Information sharing $\rightarrow$ SMEs performance & 0.149 & 0.151 & 0.024 & 6.211 & 0.000 \\
\hline Information sharing $\rightarrow$ Supply chain finance & 0.000 & 0.000 & 0.000 & 0.000 & 0.000 \\
\hline Information technology application $\rightarrow$ Innovation capability & 0.062 & 0.064 & 0.012 & 5.06 & 0.000 \\
\hline Information technology application $\rightarrow$ Market response capability & 0.023 & 0.023 & 0.008 & 2.681 & 0.007 \\
\hline Information technology application $\rightarrow$ SMEs performance & 0.064 & 0.066 & 0.013 & 5.105 & 0.000 \\
\hline Information technology application $\rightarrow$ Supply chain finance & 0.000 & 0.000 & 0.000 & 0.000 & 0.000 \\
\hline Innovation capability $\rightarrow$ SMEs performance & 0.000 & 0.000 & 0.000 & 0.000 & 0.000 \\
\hline Market response capability $\rightarrow$ SMEs performance & 0.000 & 0.000 & 0.000 & 0.000 & 0.000 \\
\hline Supply chain finance $\rightarrow$ Innovation capability & 0.000 & 0.000 & 0.000 & 0.000 & 0.000 \\
\hline Supply chain finance $\rightarrow$ Market response capability & 0.000 & 0.000 & 0.000 & 0.000 & 0.000 \\
\hline Supply chain finance $\rightarrow$ SMEs performance & 0.15 & 0.15 & 0.028 & 5.316 & 0.000 \\
\hline Supply chain integration $\rightarrow$ Innovation capability & 0.138 & 0.135 & 0.016 & 8.636 & 0.000 \\
\hline Supply chain integration $\rightarrow$ Market response capability & 0.05 & 0.049 & 0.015 & 3.284 & 0.001 \\
\hline Supply chain integration $\rightarrow$ SMEs performance & 0.142 & 0.14 & 0.017 & 8.269 & 0 \\
\hline Supply chain integration $\rightarrow$ Supply chain finance & 0 & 0 & 0 & 0 & 0 \\
\hline
\end{tabular}

This is a suggested basis for future research in different directions.

\section{Conclusion}

The world economy is changing very rapidly in all aspects. This can be seen in the fact that businesses are increasingly operating in a far-reaching and highly sophisticated supply chain. And each business only plays a certain role in the whole global supply chain. It is a fact that in Vietnam, even medium and large-sized companies just stop at how to make their businesses work effectively, not paying attention to partners in the supply chain. Meanwhile, many corporations in more developed economies such as Korea or Japan have enjoyed great success by supporting their supply chain partners. They understand that partners contribute greatly to their success, so they always introduce new opportunities from intermediary 
financial institutions to chain partners, creating conditions for partners to operate. going well. Therefore, Vietnamese businesses need a big change in thinking and vision, specifically how to come up with solutions that benefit all parties in the supply chain. Supply chain financing is one of those solutions. In a supply chain, if each business is provided with adequate capital, it will create more favorable conditions for the chain to operate. For example, enterprise A specializes in manufacturing export footwear and has many partners in the supply chain, such as a series of suppliers of input materials (rubber, glue, distribution...). If enterprise A operates efficiently with good profit growth, then A's bank can participate in trade finance and provide international payment services and related banking services to both partners. is a supplier of enterprise A. Similarly, the trade finance and service provision will be extended by the bank to include enterprises distributing to enterprise A. That is, the bank will assist in resource arrangement. capital for A's entire supply chain, enabling it to run smoothly.

According to a forecast of HSBC, within the next 10 years, trade between countries will grow by $33 \%$. This means that financing of supply chains to promote global trade will increase even more. According to HSBC's latest forecast on international trade, within the next 15 years, Vietnam's trade growth will reach $144 \%$ compared to the world's $73 \%$ growth rate. Besides the 5 traditional trading markets of Vietnam, which are Europe, the US, Japan, South Korea and Singapore, there will be 5 new markets that will bring many business and export opportunities for Vietnamese enterprises. These are the Philippines, India (with high import demand for agricultural products, technological products), Turkey (with demand for imported processed and processed goods), Switzerland (metal products and precious metals). ) and the United Arab Emirates (energy). Also according to HSBC, the value of goods traded in global trade by 2025 will reach 43.6 trillion USD, compared with the current level of 27.2 trillion USD. The main countries that will play a role in promoting world trade during this period are Egypt, India, Vietnam, Indonesia, China and Brazil. And businesses will become more deeply involved in supply chains, which are becoming increasingly complex and spanning multiple geographies. The problem is whether Vietnamese enterprises can grasp the economic trends in the world to serve their business well or not.

Against that background, combined with the research results presented above, we offer some solutions and recommendations as follows:

From the side of the banking industry, in addition to completing the system of relevant legal documents, the SBV has also directed the commercial banking system to implement supply chain financing programs. However, at present, due to the lack of transparency in the data and financial information system of many enterprises, the management capacity of small and medium-sized enterprises is still quite limited; The customer database and electronic trading platform in supply chains are also incomplete, so supply chain financing, especially global supply chains, has not yet developed commensurate with its potential.

Firstly, perfecting institutions, policies and legal systems on transparent, fair and healthy business for the purpose of continuing to improve the business environment for enterprises, creating maximum convenience for enterprises when participating in business activities. enter the domestic and foreign markets. Promulgating a system of synchronous and longterm stable policies for the operation of the SME sector. Develop diversified financial markets and stock markets to support enterprises to mobilize capital on the stock market and borrow capital on the corporate bond market. At the same time, supporting SMEs by answering legal problems, business registration; It is also possible to open more business consulting activities for businesses or set up a specialized agency to help the development of SMEs in Vietnam.

Completing the legal framework and the scope of supporting SMEs to develop in the country and integrate into the world (clearly defining the framework for the entry, operation, dissolution and bankruptcy of Vietnamese enterprises); technology, scientific and technical support for Vietnamese enterprises; developing human resources for SMEs, focusing on improving governance capacity; promote the formation of Vietnamese enterprises; provide information to support SMEs and promote market expansion; building a system of development assistance organizations; organize the implementation of programs related to the development of Vietnamese enterprises.

Second, continue to implement the Government's mechanisms and policies in reforming tariff levels, cutting down on business registration procedures along with "informal costs". Ministries and branches need to reduce unnecessary inspections and checks on SMEs, especially in the work of eliminating corruption and harassment of enterprises. There is a mechanism to cut corporate income tax to support SMEs to solve the problem of creating jobs for society, with specific regulations on using that part of corporate income tax incentives to reinvest and create jobs. new. Support and create favorable conditions for SMEs to access resources (land, finance, labor, science and technology...). Building and developing information and data infrastructure about enterprises operating in the same industry in terms of capital market, labor market, science and technology market, etc.

Third, promote the role of society, socio-political organizations, and socio-professional organizations in promoting the development of SMEs, raising the awareness of the social community for the development of SMEs in Vietnam. Vietnam. Accordingly, it is necessary to improve the role and capacity of associations to support SMEs and strengthen the function of consultation and social criticism. On the other hand, increasing the reception of feedback, opinions and needs from consumers 
using SMEs products to self-improve businesses in business activities, providing goods and services to customers with solutions. measures such as: improving social responsibility, business responsibility of enterprises towards consumers; balance the interests of traders and consumers.

Fourth, each SME itself must raise their awareness of rising up, promoting their advantages, and enhancing their competitiveness. Vietnamese SMEs have many advantages in terms of business, market scope, and customers to participate in domestic, regional and international commercial activities. Especially, in the context that Vietnam is a member of the ASEAN Economic Community (AEC), taking advantage of the inherent advantages of SMEs will promote the country's economic growth in Southeast Asia.

Capturing the needs and psychology of customers or customer groups in accordance with the type and business lines of each enterprise is also a solution that SMEs can implement and create positive results. In addition, enterprises need to have a development strategy through specific plans, strategies, visions and operational missions. A solution is also applied to SMEs, which is to build a vision in the development of their business by clearly defining economic issues, customers, competition, future orientation, prospects. of enterprises, high specialization in contact with customers, prestige, brand and core values that each enterprise provides to the market and society, etc.

In order to minimize failures such as forced dissolution, self-dissolution, business stagnation, and suspension of operations, SMEs need to identify the scope and target audience. In other words, based on size, potential and type of operation, SMEs need to have an appropriate strategy in choosing markets and market segments to exploit and do business. Choosing the right market segment is a solution and at the same time a careful and safe preparation for the stable development of each enterprise. On the other hand, each enterprise needs to effectively exploit resources to support and promote development such as: support solutions from domestic and foreign investors; policies and plans to support the State in terms of capital, finance, technology, administration, and business... At the same time, the alliance and association of business enterprises operating in the same industry under forms such as business cooperation, joint venture, joint venture... are also a suitable solution to promote their roles and strengths.

Fifth, in the context of opening and extensive international integration, Vietnam has signed a series of new generation FTAs, in order to improve competitiveness, SMEs need to know how to make the most of capital potentials, Human resources, market, culture, business experience of enterprises... This is the important self-advocacy of each SME in the plan to implement its strategies and business goals together with other SMEs. strong competitor in the market. Understanding competitors and harmonizing interests with competitors in business will create stable development opportunities for SMEs. That means, SMEs need to know how to keep a good relationship with large enterprises in the context of the fiercely competitive market. In particular, SMEs need to be transparent in their operations and financial statements, improve the quality of corporate governance, and manage risks.

For governing bodies

Firstly, continue to have policies to directly support workers and unemployment. Attention and focus on workers in micro, small and medium-sized enterprises through support to solve the problem of unemployment benefits for workers.

Second, focus more on monetary-credit support policy packages, continue to maintain the fiscal policy package through taxes and land use levy.

\section{Strengthening the role of business associations}

In the process of international integration, in addition to support from the Government for businesses, support measures through associations are also necessary. The role of associations is not only to represent enterprises, to help enterprises in business, but also to support enterprises in labor relations, legal advice, training and corporate social responsibility. Vietnam needs to form a supply chain financing association to support businesses and credit institutions to connect and participate in global supply chains. In addition, this activity needs the encouragement and participation of the Government to promote and support small and medium enterprises to access supply chain finance products, thereby enhancing their competitiveness. of businesses in the market. Vietnamese small and medium enterprises and banks are still not fully aware of the supply chain market and consider it a normal loan product. Therefore, to promote this market to develop supply chain financing services, factoring must be included in current legal documents. The transparency and legalization of the supply chain financing market will help Vietnam can promote businesses, especially small and medium enterprises, to develop.

\section{References}

Ali, Z., Gongbing, B., \& Mehreen, A. (2020). Does supply chain finance improve SMEs performance? The moderating role of trade digitization. Business Process Management Journal, 26(1), 150-167.

Baihaqi, I., \& Sohal, A. S. (2013). The impact of information sharing in supply chains on organisational performance: an empirical study. Production Planning \& Control, 24(8-9), 743-758. 
Camerinelli, E. (2009). Supply chain finance. Journal of Payments Strategy \& Systems, 3(2), 114-128.

Caniato, F., Gelsomino, L. M., Perego, A., \& Ronchi, S. (2016). Does finance solve the supply chain financing problem?, Supply chain management: an international journal, 21(5), 534-549.

Carnovale, S., Rogers, D. S., \& Yeniyurt, S. (2019). Broadening the perspective of supply chain finance: The performance impacts of network power and cohesion. Journal of Purchasing and Supply Management, 25(2), 134-145.

Chin, W. W. (2010). How to write up and report PLS analyses. In Handbook of partial least squares (pp. 655-690). Springer, Berlin, Heidelberg.

Chang, S., Gong, Y., Way, S. A., \& Jia, L. (2013). Flexibility-oriented HRM systems, absorptive capacity, and market responsiveness and firm innovativeness. Journal of Management, 39(7), 1924-1951.

Dubey, R., Gunasekaran, A., Childe, S. J., Papadopoulos, T., Blome, C., \& Luo, Z. (2017). Antecedents of resilient supply chains: An empirical study. IEEE Transactions on Engineering Management, 66(1), 8-19.

Frohlich, M. T., \& Westbrook, R. (2001). Arcs of integration: an international study of supply chain strategies. Journal of operations management, 19(2), 185-200.

Flynn, B. B., Huo, B., \& Zhao, X. (2010). The impact of supply chain integration on performance: A contingency and configuration approach. Journal of operations management, 28(1), 58-71.

Gomm, M. L. (2010). Supply chain finance: applying finance theory to supply chain management to enhance finance in supply chains. International Journal of Logistics: Research and Applications, 13(2), 133-142.

Garrett, R. P., Covin, J. G., \& Slevin, D. P. (2009). Market responsiveness, top management risk taking, and the role of strategic learning as determinants of market pioneering. Journal of Business Research, 62(8), 782-788.

Hair, J. F., Ringle, C. M., \& Sarstedt, M. (2011). PLS-SEM: Indeed a silver bullet. Journal of Marketing theory and Practice, 19(2), 139-152.

Hair Jr, J. F., Hult, G. T. M., Ringle, C. M., \& Sarstedt, M. (2021). A primer on partial least squares structural equation modeling (PLS-SEM). Sage publications.

Hair, J. F., Henseler, J., Dijkstra, T. K., \& Sarstedt, M. (2014). Common beliefs and reality about partial least squares: comments on Rönkkö and Evermann.

Hair Jr, J. F., Sarstedt, M., Ringle, C. M., \& Gudergan, S. P. (2017). Advanced issues in partial least squares structural equation modeling. saGe publications.

Henseler, J., Ringle, C. M., \& Sarstedt, M. (2015). A new criterion for assessing discriminant validity in variance-based structural equation modeling. Journal of the academy of marketing science, 43(1), 115-135.

Henseler, J., Ringle, C. M., \& Sinkovics, R. R. (2009). The use of partial least squares path modeling in international marketing. In New challenges to international marketing. Emerald Group Publishing Limited.

Martin, J., \& Hofmann, E. (2019). Towards a framework for supply chain finance for the supply side. Journal of Purchasing and Supply Management, 25(2), 157-171.

Le, T., Nguyen, T., Phan, T., Tran, M., Phung, X., Tran, T., \& Giao, K. (2019). Impact of corporate social responsibility on supply chain management and financial performance in Vietnamese garment and textile firms. Uncertain Supply Chain Management, 7(4), 679-690.

Lee, H. L., \& Whang, S. (2000). Information sharing in a supply chain. International journal of manufacturing technology and management, 1(1), 79-93.

Linnenluecke, M. K. (2017). Resilience in business and management research: A review of influential publications and a research agenda. International Journal of Management Reviews, 19(1), 4-30.

Li, H., Mai, L., Zhang, W., \& Tian, X. (2019). Optimizing the credit term decisions in supply chain finance. Journal of Purchasing and Supply Management, 25(2), 146-156.

Li, S., \& Chen, X. (2019). The role of supply chain finance in third-party logistics industry: a case study from China. International journal of logistics research and applications, 22(2), 154-171.

Lu, Q., Liu, B., \& Song, H. (2020). How can SMEs acquire supply chain financing: The capabilities and information perspective, Industrial Management \& Data Systems, 120(4), 784-809.

Marucheck, A., Greis, N., Mena, C., \& Cai, L. (2011). Product safety and security in the global supply chain: Issues, challenges and research opportunities. Journal of operations management, 29(7-8), 707-720.

Narasimhan, R., \& Das, A. (1999). Manufacturing agility and supply chain management practices. Production and Inventory Management Journal, 40(1), 4.

Singh, N. P., \& Singh, S. (2019). Building supply chain risk resilience: Role of big data analytics in supply chain disruption mitigation. Benchmarking: An International Journal, 6(7),2318-2342.

Nguyen, T., Pham, T., Phan, T., \& Than, T. (2020). Impact of green supply chain practices on financial and non-financial performance of Vietnam's tourism enterprises. Uncertain Supply Chain Management, 8(3), 481-494.

Nagati, H., \& Rebolledo, C. (2013). Supplier development efforts: The suppliers' point of view. Industrial marketing management, 42(2), 180-188.

Phan, T., Doan, X., \& Nguyen, T. (2020). The impact of supply chain practices on performance through supply chain integration in textile and garment industry of Vietnam. Uncertain Supply Chain Management, 8(1), 175-186.

Phan, T. T. H., Tran, H. X., Le, T. T., Nguyen, N., Pervan, S., \& Tran, M. D. (2020). The Relationship between Sustainable Development Practices and Financial Performance: A Case Study of Textile Firms in Vietnam. Sustainability, 12(15), 5930. 
Pham, T., \& Phan, T. (2020). How to improve financial performance of tourism and travel enterprises: The case of Vietnam. Accounting, 6(3), 335-344.

Pfohl, H. C., \& Gomm, M. (2009). Supply chain finance: optimizing financial flows in supply chains. Logistics research, 1(34), 149-161.

Punniyamoorthy, M., Thamaraiselvan, N., \& Manikandan, L. (2013). Assessment of supply chain risk: scale development and validation. Benchmarking: An International Journal, 20(1), 79-105.

Revilla, E., \& Saenz, M. J. (2017). The impact of risk management on the frequency of supply chain disruptions: a configurational approach. International Journal of Operations \& Production Management, 37(5), 557-576.

Sharma, S., \& Routroy, S. (2016). Modeling information risk in supply chain using Bayesian networks. Journal of Enterprise Information Management, 29(2), 238-254.

Shen, B., \& Li, Q. (2017). Market disruptions in supply chains: a review of operational models. International transactions in operational research, 24(4), 697-711.

Song, H., Yu, K., Ganguly, A., \& Turson, R. (2016). Supply chain network, information sharing and SME credit quality. Industrial Management \& Data Systems, 116(4), 740-758.

Song, H., \& Wang, L. (2013). The impact of private and family firms' relational strength on financing performance in clusters. Asia Pacific Journal of Management, 30(3), 735-748.

Subramani, M. (2004). How do suppliers benefit from information technology use in supply chain relationships?. MIS quarterly, 45-73.

Swaminathan, J. M., \& Tayur, S. R. (2003). Models for supply chains in e-business. Management Science, 49(10), $1387-1406$.

Tagoe, N., Nyarko, E., \& Anuwa-Amarh, E. (2005). Financial challenges facing urban SMEs under financial sector liberalization in Ghana. Journal of small business Management, 43(3), 331-343.

Tomlinson, P. R. (2011). Strong ties, substantive embeddedness and innovation: Exploring differences in the innovative performance of small and medium-sized firms in UK manufacturing. Knowledge and Process Management, 18(2), 95108.

Tran, M., Phan, T., Ha, H., \& Hoang, T. (2020). The impact of transactional leadership on supply chain quality and performance. Uncertain Supply Chain Management, 8(4), 773-784.

Tran, M., Phan, T., Ha, H., \& Hoang, T. (2020). The impact of supply chain quality integration on green supply chain management and environmental performance in Vietnam's tourism industries. Uncertain Supply Chain Management, 8(4), 693-704.

Wuttke, D. A., Rosenzweig, E. D., \& Heese, H. S. (2019). An empirical analysis of supply chain finance adoption. Journal of Operations Management, 65(3), 242-261.

Xu, X., Chen, X., Jia, F., Brown, S., Gong, Y., \& Xu, Y. (2018). Supply chain finance: A systematic literature review and bibliometric analysis. International Journal of Production Economics, 204, 160-173.

Yu, Y., Xiong, W., \& Cao, Y. (2015). A conceptual model of Supply Chain Risk Mitigation: the role of supply chain integration and organizational risk propensity. Journal of Coastal Research, 73(10073), 95-98.

Yu, Z., Yan, H., \& Cheng, T. E. (2001). Benefits of information sharing with supply chain partnerships. Industrial management \& Data systems, 101(3), 114-121.

Zhao, L., Huo, B., Sun, L., \& Zhao, X. (2013). The impact of supply chain risk on supply chain integration and company performance: a global investigation. Supply Chain Management: An International Journal, 18(2), 115-131.

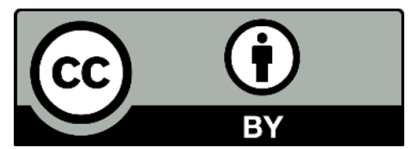

(C) 2022 by the authors; licensee Growing Science, Canada. This is an open access article distributed under the terms and conditions of the Creative Commons Attribution (CCBY) license (http://creativecommons.org/licenses/by/4.0/). 